\title{
JULIO VERNE E A VOLT AO MUNDO EM OITENTA DIAS. UMA REFLEXÃO SOBRE O ORIENTALISMO NA LITERATURA OITOCENTISTA.
}

\author{
Eduardo José de Araújo \\ Maybel Sulamita \\ Willian Funke
}

Resumo: Partindo do pressuposto de que a história como conhecimento é uma representação do passado, e que toda fonte documental que produz esse conhecimento também é, procuraremos apresentar aqui algumas reflexões acerca das relações estabelecidas entre a história e a literatura e sobre a utilização de fontes literárias na pesquisa histórica. Nesse sentido, inserimos a obra de Júlio Verne "A Volta ao Mundo em 80 dias" buscando um panorama histórico influenciado pelo século XIX, a história de uma dupla de europeus que faz uma viagem ao redor do globo correndo contra o tempo. Podemos perceber um convite a desbravar terras desconhecidas ou uma apologia ao desenvolvimento técnico e, observamos a representação do período, que inclui o Imperialismo e o Eurocentrismo, analisando conceitos sobre o tema, percebemos discursos de superioridade justificadores de algumas atitudes e as incorporações do outro enquanto inferior.

Palavras-chaves: Imperialismo; Literatura; Julio Verne.

Abstract: Assuming that history as knowledge is a representation of the past and all documented source that produces this knowledge is also, through this study will try to present some reflections on the relations between history and literature and the use of literary sources in historical research. In this sense, the work of Jules Vernes Around the World in 80 days is a story influenced for nineteenth century, it is the story of an adventure about two mens, passing through various difficulties, making a trip to around the globe, racing against time, we can see an invitation to brave unknown lands or an apology for technical development. In this work of Jules Verne, can be see a representation of your period, which - among other things - include Imperialism and Eurocentrism, to analyze concepts pertaining to this issue, it is possible to realize discourses of superiority by which to justify attitudes and the incorporation of other lower settings.

Keys-words: Imperialism, Literature, Jules Verne. 
"Tudo que uma pessoa pode imaginar, outras podem tornar real. "Julio Verne

\section{Introdução}

Ao lermos o livro "A Volta ao Mundo em 80 dias" podemos ter diversas impressões. Lendo apenas por mera diversão teremos uma aventura de uma dupla dinâmica, que passando pelas mais variadas dificuldades, faz uma viagem ao redor do globo correndo contra o tempo, ou a favor, dependendo do ponto de vista. Lendo como alguém do século XIX, podemos ver a obra como um convite a desbravar terras desconhecidas ou uma apologia ao desenvolvimento técnico. Como estudantes de história do presente, vemos nesse livro de Júlio Verne a representação de seu período, que - entre outras coisas - incluí o Imperialismo.

Vemos o Imperialismo em alguns aspectos, destacando os discursos de superioridade pelo qual se justificam algumas atitudes e se incorpora o "outro" enquanto inferior. Não se esquecendo do avanço tecnológico, mote do livro e que também pode ser lido de modo a corroborar nossa interpretação, além da burocracia, que também tem papel importante na trama. 
Na sequência apresentamos uma breve discussão sobre o uso de literatura como fonte histórica. Passamos para algumas informações e reflexões sobre a vida do autor. Chegando então à discussão da problemática proposta. Encerrando com algumas considerações à guiza de conclusão.

\section{Literatura e História}

Partindo do pressuposto de que a história como conhecimento é uma representação do passado e que toda fonte documental que produz esse conhecimento também o é, procuraremos apresentar aqui algumas reflexões acerca das relações estabelecidas entre a história e a literatura sobre a utilização de emprego das fontes literárias na pesquisa histórica. Em diversos estudos atuais, percebemos a ligação do estudo historiográfico em paralelo com obras literárias como fontes, mas antes de uma simples abordagem há que se reforçar a própria obra como uma precursora de algo em si mesmo, implicada em seu momento de produção e sua transmissão de ideias.

A recepção de uma obra é particular, ou nas palavras de Chartier:

(...) devemos romper com a atitude espontânea que supõe que todos os textos, todas as obras, todos os gêneros, foram compostos, publicados, lidos e recebidos segundo 
os critérios que caracterizam nossa própria relação com o escrito ${ }^{1}$.

Identificar o contexto e também relacionar a obra com discussões pertinentes do presente se mostra como uma tarefa, pois vários elementos construtivos que formam um todo, ou seja, o contexto social, moral e político estão inseridos de maneira intrínseca, a partir destes pontos podemos chegar ao seu foco.

Assim a literatura, como testemunho histórico, é fruto de um processo social e apresenta propriedades específicas que precisam ser interrogadas. Resta a nós descobrir, ponderar e detalhar sobre as condições de sua produção ${ }^{2}$.

\section{Júlio Verne e sua obra}

Júlio Verne nasceu em Nantes (1828 -1905), filho mais velho dos cinco filhos de Pierre Verne, advogado, e Sophie Allote de la Fuÿe. Sua adolescência transcorreu entre contínuos choques com o pai, para quem os desejos exploratórios e literários de Júlio pareciam totalmente ridículos. Quando adulto conseguiu mudar-se para Paris onde entrou em

\footnotetext{
${ }^{1}$ CHARTIER, Roger. Literatura e História. Conferência proferida em 5 de novembro de 1999, no Salão Nobre do Instituto de Filosofia e Ciências Sociais, que abriu o debate que se segue com João Adolfo Hansen. Disponível em: http://www.revistatopoi.org/numeros_anteriores/Topoi01/01_debate01.pdf pg. 197 2 BORGES, Valdeci Rezende. "História e Literatura: Algumas Considerações". Revista de Teoria da História Ano 1, Número 3, junho/ 2010. pg. 103
} 
contato com os mais prestigiados literatos da época, como por exemplo, Alexandre Dumas. Em 1850 concluiu seus estudos jurídicos e, apesar da insistência do pai para que voltasse a Nantes, resistiu firmemente na decisão de tornar-se um profissional das letras. Durante essa época que Verne, influenciado pelas conquistas científicas e técnicas da época, decidiu criar uma literatura adaptada à idade científica. Assim, vertendo todos estes conhecimentos em relatos épicos, enaltecendo o gênio e a fortaleza do homem em sua luta por dominar e transformar a natureza seguiu o conselho de um amigo, o editor P. J. Hetzel, que seria seu editor in eternum, e converteu um relato descritivo da África na obra Cinco semanas em um balão (1863), obtendo êxito imediato. Firmou um contrato de vinte anos com Hetzel. E assim, por mais de quarenta anos, as Viagens Extraordinárias, como são chamadas as obras desse período do escritor, apareceram em capítulos mensais na Magasin D'éducation et de Récréation (Revista de Educação e Recreação).

Julio Verne é considerado por críticos literários o precursor do gênero de ficção científica, tendo feito predições em seus livros sobre o aparecimento de novos avanços científicos, como os submarinos, máquinas voadoras e viagem à Lua, até hoje Verne é um dos escritores cuja obra foi mais traduzida em toda a história, com traduções em 148 
línguas, segundo estatísticas da UNESCO, tendo escrito mais de 100 livros ${ }^{3}$.

Poderíamos então dizer que Verne era um homem a frente de seu tempo? Acreditamos que não. $\mathrm{Na}$ verdade consideramos o francês alguém de seu próprio tempo, o que parece óbvio. Mas não deixamos de atribuir ao literato uma sensibilidade digna de nota, tendo em vista que consegue captar com maestria o que podemos chamar de espírito de seu tempo. Faz uso de acontecimentos, locais e condições verídicas - no mínimo verossímeis - para ambientar suas histórias e as conta de modo envolvente. Não podemos deixar de sentir o sangue correr mais rápido quando Phileas Fogg se compromete com a aposta. Além das qualidades narrativas, o sucesso editorial de Verne é resultado da relação que se estabelece entre o que o público deseja consumir e o autor consegue produzir, atendendo aos anseios de seu público.

Antes de passarmos a um breve resumo do livro, outra questão que nos chamou a atenção foi o fato de Julio Verne, um francês, eleger para personagem principal desse seu relato um inglês, em posição de superioridade hierárquica em relação ao criado francês. Acreditamos que, ao longo do livro, apesar da diferença existente entre inglês e francês, patrão e empregado, o que os torna iguais é o fato de serem europeus e estarem juntos na jornada, na qual o criado só se engaja

\footnotetext{
3 Disponível em:_http://juliovernebrasil.blogspot.com.br/p/quem-foi-julio-verne.html acesso em 20 de julho de 2013.
} 
verdadeiramente quando já está em curso. Uma análise mais livre pode nos apresentar ainda a possibilidade de haver uma complementação entre elementos do inglês e do francês, para vencer as dificuldades e conquistar o mundo seria necessário reunir a frieza britânica ao ímpeto galicano, mas isso fica para outras viagens.

Quanto à obra literária analisada, o livro $A$ volta ao mundo em 80 dias, escrita na metade do século XIX, trata-se da história de um inglês bem-educado, culto e rico chamado Phileas Fogg. No início do livro, o Sr. Fogg recebe em sua casa o seu novo criado particular, o francês Fura-Vidas. Nesse mesmo dia, enquanto jogava whist com outros membros do Reform Club e discutia o recente assalto ao banco de Inglaterra, Fogg afirma que seria possível ao ladrão em fuga dar a volta ao mundo em oitenta dias. Esta afirmação causou uma discussão entre os jogadores que acabam por fazer uma aposta com Phileas Fogg: Stuart, Fallentin, Sullivan, Flanagan e Ralph apostaram quatro mil libras contra vinte mil libras de Fogg em como este não conseguiria dar a volta ao mundo em oitenta dias. Feita a aposta, Phileas partiria nessa mesma noite, no dia 2 de Outubro, e regressaria a Londres dia 21 de Dezembro, quando faltassem exatamente quinze minutos para as nove da noite. E foi assim que, acompanhado por seu criado, o herói inicia sua grande aventura.

Após ter ultrapassado Paris, Turim e Brindisi, foi em Suez que Fogg se tornou suspeito do teimoso detetive da Scotland Yard, Sr. Fix, 
que encontrou várias semelhanças entre o Phileas e o assaltante do banco de Inglaterra. $\mathrm{O}$ detetive imediatamente pede um mandado de captura para Londres. A partir daqui, Phileas Fogg foi permanentemente perseguido pelo detetive Fix. Os dois companheiros seguem viagem desde o Egito à Índia, depois a China, o Japão, os Estados Unidos e, finalmente regressam a Inglaterra. $\mathrm{Na}$ sua jornada usam diferentes meios de transporte da época: vapores, comboios, carruagem, e até mesmo um elefante. São também várias as personagens com quem se cruzam e criam amizade. É o caso de Aouda, uma bela indiana que seria sacrificada, o que exploraremos adiante. Os sentimentos entre Fogg e Aouda vão crescendo ao longo da viagem. Desconhecendo o verdadeiro assaltante do banco de Inglaterra, o detetive Fix prende Fogg quando este chega ao cais de Liverpool. Este acontecimento acaba por atrasar o nosso herói. Após ter sido libertado, acaba por verificar que perdera a aposta por cinco minutos; desanimado segue para casa com Aouda e Fura- Vidas. No dia seguinte, Fura-Vidas dirige-se ao Reverendo Samuel Wilson para marcar o casamento entre Fogg e Aouda. É então que descobre que estão no Sábado e não Domingo, assim não teriam perdido a aposta. Como a viagem fora feita sempre em direção a Oriente, isto é, contra o sol, os dias diminuíram tantas vezes que acabaram por ganhar um dia! Fogg ganha à aposta e o coração da mulher amada. 


\section{Análise}

Dentro de A volta ao mundo em 80 dias, podemos perceber o ponto de vista europeu sobre o restante do mundo, que se tornava cada vez mais próximo devido as relações políticas e econômicas crescentes. Esse "novo mundo" se apresenta no livro como uma construção de um paradigma de hierarquização entre as sociedades que se encontram um mundo em formação e desconhecido para a maioria. E a partir desse desconhecido cria-se e propaga-se um discurso que estigmatiza o outro, o coloca em posição de inferioridade e em condição de ser dominado. Este processo é proposto e desenvolvido por Edward Said em seu livro Orientalismo. ${ }^{4}$

Nosso entendimento deste conceito será um dos norteadores da análise que segue. Outra autora que embasou nossa leitura foi Hannah Arendt, principalmente seus conceitos de raça e burocracia, os quais ficam mais bem explicados nas palavras da própria autora:

a raça foi descoberta na África do Sul e a burocracia na Argélia, Egito e Índia; a primeira foi inicialmente a reação quase inconsciente diante de tribos cuja humanidade atemorizava e envergonhava o homem europeu, enquanto a segunda resultou da aplicação de princípios administrativos através dos quais os europeus haviam

${ }^{4}$ SAID, Edward W. Introdução. In.: Orientalismo. O Oriente como invenção do Ocidente. São Paulo: Companhia das Letras, 1990. 13-39. 
tentado dominar povos estrangeiros considerados carentes e de sua proteção especial. ${ }^{5}$

Notadamente uma das primeiras características da obra de Júlio Verne, é a marcação de divisas entre dois mundos: o romance se inicia na cidade Londres no século XIX, mostrando a atuação de nobres, empresários e cavalheiros, ou seja, "tipos ideais" em um clube elegante e suntuoso, as regiões que eram ou tinham sido domínios ingleses na época também aparecem na obra com grande e clara influência britânica por todos os continentes. Através de recortes geográficos baseados nesse domínio o autor nos apresenta um mundo exótico e absolutamente diferente do qual se vivia moldado pelos padrões ingleses, nas páginas desta obra registra-se o olhar europeu e toda curiosidade e assombro dos europeus que a conheciam.

\section{Personagens e a visão sob os "outros"}

$\mathrm{Na}$ obra de Júlio Verne, também percebemos que alguns personagens específicos orientam a obra acerca da problemática proposta neste trabalho. Pela visão deles observamos o que compreendemos como orientalismo, esse olhar de estranhamento frente ao "outro" é perceptível na figura do servo de Fogg: o francês Fura-

\footnotetext{
5 ARENDT, Hannah. Raça e burocracia. In: Origens do Totalitarismo. São Paulo: Companhia das Letras, 1989. p 224.
} 
vidas. Através de seu olhar conheceremos os diversos países, e encontraremos as diversas descrições ligadas ao exótico e diferente desse "novo mundo" dominados pelo poder inglês; esse domínio ao longo do livro é citado várias vezes como benéfico e liberal, como observamos no trecho a seguir, a entrada de visitantes calçados em templos sagrados na Índia, o governo inglês teria o controle para não haver desrespeitos, e assim o narrador afirma: "devemos ainda notar que, em virtude de razões de boa política, o governo inglês, respeitando e fazendo respeitar até nos seus mais insignificantes pormenores a religião do país, pune severamente todo aquele que lhe ofende as práticas" ${ }^{\prime 6}$.

Ou seja, o domínio inglês selecionava em quais costumes locais iria intervir, a lógica era sempre a do paternalismo e a da subordinação, costumes religiosos eram considerados "curiosidade" e tolerados primeiramente enquanto não propiciassem qualquer tentativa de mudança no quadro de dominação, não promovessem nenhuma forma de resistência ou ainda, apesar de isso estar em segundo plano, quando não causassem afronta à moral europeia:

ideias de levar a civilização a povos bárbaros ou primitivos, a noção incomodamente familiar de se fazia necessário o açoitamento, a morte ou um longo castigo

\footnotetext{
6 VERNE, Júlio. A Volta ao Mundo em 80 Dias. Companhia Distribuidora de Livros São Paulo, 1970 pg. 51.
} 
quando 'eles' se comportavam mal ou se rebelavam, porque em geral o que 'eles' melhor entendiam era a força ou a violência; 'eles' não eram como 'nós', e por isso deviam ser dominados (SAID 1995: 11-12).

$\mathrm{Na}$ visita a Índia temos destaque também para outro personagem central da trama, a indiana Auoda, resgatada de um sacrifício pertencente à cultura, intitulada sutty, definido por Fogg como um costume bárbaro, percebemos nessa parte que Auoda apesar de indiana é descrita na obra com aparência de uma "jovem, clara e européia", nesse sentido a única mulher presente na trama é inserida por se aproximar dos padrões europeus do contexto da viagem realizada por Fogg.

No enredo a burocracia é encarnada por mais de um personagem secundário, como os fiscais dos portos, juízes na Índia, mas nenhum outro serve melhor ao nosso propósito que o inspetor Fix. $\mathrm{O}$ agente da polícia Metropolitana de Londres acredita firmemente na culpa de Fogg no caso do roubo ao banco, assim persegue a partir de Londres dando a volta em todo globo em 80 dias na tentativa de capturar o excêntrico apostador. Nas áreas de sua jurisdição, sob domínio do Império Britânico (nomeadamente no Egito, na Índia e na China), Fix faz o que está ao seu alcance para atrasar a viagem de Fogg e Fura-Vidas, de

\footnotetext{
${ }^{7}$ Ibidem, pg. 64.
} 
modo que o mandado de prisão que mandou expedir o alcance e possa encarcerar o seu suspeito ${ }^{8}$.

Temos aqui, de modo sutil, a possibilidade de agência de um elemento britânico, o agente Fix, em áreas fora de seu país, mas que estavam sob domínio da Coroa, de modo a garantir a justiça e a segurança em todo o mundo, ao menos o subordinado à Rainha. Da mesma forma que Fix expediu um mandado de prisão para Fogg, poderia tê-lo feito para um indiano do qual suspeitasse. Quando impossibilitado de agir por estar fora de terras de sua majestade, o detetive se esforçará para que o apostador retorne a Inglaterra no prazo e lá possa prendê-lo.

Ao longo da viagem não podemos deixar passar o avanço técnico e tecnológico que possibilita aos viajantes completarem a jornada no prazo estipulado. Eric Hobsbawm comenta a história de Verne em um capítulo de A Era do Capital, sugestivamente chamado "O mundo unificado". O historiador inglês enfatiza a importância da expansão das estradas de ferro na possibilidade da consecução dos objetivos do protagonista da trama, uma vez que a velocidade das máquinas (trens e vapores) não teria se modificado tanto no quarto de século que vai de 1848 a 1872 . Se considerarmos que o Imperialismo

8 O mandado de prisão é solicitado no capítulo VIII chamado Fura-Vidas fala demasiado, e as intervenções do detetive Fix se repetem em diversos capítulos seguintes.

9 HOBSBAWM, Eric. O mundo unificado. In.: A Era do Capital. 1848-1875. São Paulo: Paz e Terra, 1982. 63-82. 
consiste em dominar territórios na intenção de dominar outros ainda, a expansão da rede ferroviária, e consequentemente das comunicações, terá papel importante na realização desse fim, uma vez que reduz o tempo gasto para o deslocamento entre um ponto e outro do Império Britânico, por exemplo.

No nível do discurso, ainda que não envolva dominação, algo que nos chama a atenção e a forma como são descritos os estadunidenses, turrões, brigões e mais corajosos que inteligentes. ${ }^{10} \mathrm{Um}$ arrogante militar americano consegue tirar nosso impávido inglês do sério, chegando mesmo a ocorrer confronto físico. Fura-Vidas é sequestrado por índios selvagens. E o mesmo Fura-Vidas não é ouvido quando da resolução de um problema, no qual as características dos excolonos se tornam mais evidentes. O trem no qual estavam a bordo para diante de uma ponte que estava para cair. Inicia-se um impasse, pois não se sabia o que seria feito para transpor a ponte, uns dizem que não é possível, outros afirmam que é viável, até o maquinista dar a ideia que passando pela ponte a todo vapor o trem estaria do outro lado antes que a construção ruísse. Os passageiros concordam alguns hesitantes, e no fim a previsão do maquinista se confirma, mas a ponte desaba. FuraVidas reconhece o êxito, mas fica perplexo por não terem pensado em

\footnotetext{
10 A parte da história que se passa nos Estados Unidos é contada entre os capítulos XXV "Comício em São Francisco" e XXXI. "Em trenó à vela".
} 
esvaziar o trem, atravessando os passageiros e as bagagens e depois o veículo, bem mais leve. ${ }^{11}$

Por fim gostaríamos de destacar o posicionamento do personagem principal, Phileas Fogg ao longo do livro. É mais evidente identificar o estranhamento em relação ao outro e os conflitos que isso gera. Mas é de extrema relevância a atitude do inglês. Ele não se interessa pelos lugares, pelos costumes, pelas culturas, a não ser quando entram em jogo valores, como quando coloca em risco sua aposta, e mesmo a vida para salvar Aouda e Fura-Vidas. ${ }^{12}$ Mas Fogg volta logo em seguida ao estado normal, correndo apenas para chegar ao Reform Club no dia combinado para o fim da aposta. Quando chegam ou passam por algum lugar, sempre se menciona que o apostador ficará em sua cabine, foi direto ao hotel, ou se entreteve em uma partida de cartas. Consideramos que esse comportamento demonstra como não é importante para o senhor Fogg a viagem em si, ela é apenas um meio, mas o interesse dele se inicia e se encerra em Londres, não sendo nem mesmo vantagens materiais:

A vida nativa forrava esses eventos fantasmagóricos com aparente garantia contra quaisquer consequências, uma vez que os nativos pareciam a esses homens 'mero movimento de sombras. Sombras em movimento, a raça

\footnotetext{
${ }^{11}$ Essa descrição está presente no capítulo XXV "Comício em São Francisco".

12 Capítulos XII "Através da floresta" e XIII "A fortuna sorri aos audaciosos" no primeiro caso e XXX "Phileas Fogg cumpre seu dever" no segundo.
} 
dominante podia caminhar entre elas impunemente e sem ser percebida, em busca de seus incompreensíveis propósitos e necessidades ('Heart of darkness') ${ }^{13}$.

\section{Conclusões}

Apesar de todo o "franco triunfalismo" 14 do autor, os conflitos com nativos que são muito presentes na narrativa deixam entrever a capacidade desses povos de se rebelarem contra a dominação:

O contato imperial nunca consistiu na relação entre um ativo intruso ocidental contra um nativo ocidental inerte ou passivo; sempre houve algum tipo de resistência ativa e, na maioria esmagadora dos casos essa resistência acabou preponderando. ${ }^{15}$.

O conflito com os nativos da América do Norte, a prisão de Fura-Vidas no templo e a perseguição por ocasião do "resgaste" de Aouda na Índia são exemplos de que mesmo os europeus do séc. XIX não confiavam completamente nas propagandas das empresas coloniais e dos governos dessas potências que dominavam o mundo, vemos pelo contrário, o terror que qualquer ação enérgica dos colonizados causavam a essa Europa vencedora que buscava por qualquer meio aniquilar qualquer resistência.

13 ARENDT, Hanna. Origens do Totalitarismo. Companhia das Letras 1989, pg.220.

${ }^{14}$ SAID, Edward W. Cultura e Imperialismo. Companhia das Letras 1995, pg 18.

15 Ibidem, pg. 12. 
Procuramos dar nesse trabalho um panorama contextual do séc. XIX a partir das lentes da literatura nos utilizando dos conhecimentos que são possíveis com os acúmulos políticos e teóricos alcançados no séc. XXI, nosso país também esteve inserido nos processos de hierarquização política, racial, social e cultural em relação a esse Ocidente e obras como "A volta ao mundo em oitenta dias" estão amplamente disseminadas no nosso meio. Longe de propormos aqui qualquer tipo de censura a ela, acreditamos que a reflexão sobre essa possível interpretação que demonstramos nesse trabalho é muito necessária no sentido de propiciar primeiro o melhor conhecimento sobre a nossos processos constitutivos, segundo o reconhecimento das possíveis continuidades de discursos que Júlio Verne apresentou ainda em dias atuais.

Baseados em Edward Said compreendemos que a produção cultural e nesse caso, a literatura não está separada do contexto da vida prática na História e um dos objetivos desse trabalho também é o de nos contrapormos às ideias de "arte pela arte" ou, "cultura pela cultura" que estão tão em voga em tempos de produção cultural mercadológica e em massa.

Pensando em Carlyle ou Ruskin, ou mesmo em Dickens e Thackeray, a meu ver os críticos com frequência tem relegado as ideias desses escritores sobre a expansão colonial, as raças infeiores ou os 'negros' a um departamento muito diferente do que da cultura, sendo 
esta a área elevada de atividades a que eles 'realmente' pertencem e em que elaboram suas obras 'realmente' importantes. A cultura concebida dessa maneira, pode se tornar uma cerca de proteção: deixe a política na porta antes de entrar ${ }^{16}$.

Não vivemos senão, as consequências do colonialismo assim a hierarquização ainda é utilizada como justificativa para exploração econômica, intervenções violentas e mesmo a manutenção do status de certos países nesse período do Capitalismo globalizado.

\section{Referências}

ARENDT, Hannah. Origens do Totalitarismo. Companhia das Letras 1989

CHARTIER, Roger. Literatura e História. Conferência proferida em 5 de novembro de 1999. Disponível em: http://www.revistatopoi.org/numeros_anteriores/Topoi01/01_debate01. pdf pg. 197

BORGES, Valdeci Rezende. "História e Literatura: Algumas Considerações". Revista de Teoria da História. Ano 1, Número 3, junho/ 2010

${ }^{16}$ Ibidem, pg. 14 
Revista Vernáculo, $n^{o} 30,2^{\circ}$ sem/2012

HOBSBAWM, Eric. A Era do Capital. 1848-1875. São Paulo: Paz e Terra, 1982

SAID, Edward W.. Cultura e Imperialismo. Companhia das Letras 1995

SAID, Edward W. Introdução. In.: Orientalismo. O Oriente como invenção do Ocidente. São Paulo: Companhia das Letras, 1990.

VERNE, Júlio. A Volta ao Mundo em 80 Dias. Companhia Distribuidora de Livros São Paulo, 1970. 